\title{
Two cases of gastric cancer with peritoneal carcinomatosis successfully responding to combination chemotherapy of S-1 and cisplatin, leading to clinical complete response
}

\author{
Shuhei Suzuki - Yuriko Ito - Tadahisa Fukui - Mika Orihara · \\ Sho Nakamura • Masahiro Takahashi · Hiroto Fujimoto • \\ Wataru Kimura · Takashi Yoshioka
}

Received: 16 November 2012/ Accepted: 8 February 2013/Published online: 1 March 2013

(C) The Japan Society of Clinical Oncology 2013

\begin{abstract}
We report two cases of gastric cancer with peritoneal carcinomatosis successfully responding to combination chemotherapy of S-1 and cisplatin, leading to a clinical complete response (cCR). In case 1, a 60-year-old woman achieved a cCR after 6 cycles of S-1 and cisplatin. Eight cycles of S-1 and cisplatin and 16 cycles of S- 1 alone were administered. Since treatment with S-1 alone, only observation has been performed with no recurrence. In case 2, a 63-year-old man achieved cCR after 2 cycles of S-1 and cisplatin chemotherapy. After 8 cycles of chemotherapy, cCR was confirmed, and a curative operation was performed. After surgery, a small number of viable cells were found in the pathological examination. Fifty-four reports of cCR cases of advanced non-resectable or metastatic gastric cancer with chemotherapy have been published, but none mentioned the treatment options after cCR. In this report, we show two patients choosing different paths after achieving cCR by chemotherapy. In our surgical case, residues of pathologically viable cancer cells were confirmed, so surgery might be recommended after cCR, but further investigation will be needed.
\end{abstract}

Keywords Gastric cancer - Clinical complete response · Cisplatin $\cdot$ S-1 $\cdot$ Chemotherapy

S. Suzuki · Y. Ito $(\bowtie) \cdot$ T. Fukui · M. Orihara - S. Nakamura · M. Takahashi · T. Yoshioka

Department of Clinical Oncology, Yamagata Faculty of Medicine, Yamagata University, 2-2-2 Iida-nishi,

Yamagata 990-9585, Japan

e-mail: i.yuriko@med.id.yamagata-u.ac.jp

H. Fujimoto · W. Kimura

First Department of Surgery, Yamagata Faculty of Medicine,

Yamagata University, 2-2-2 Iida-nishi, Yamagata, Japan

\section{Introduction}

Gastric cancer is the most common neoplasm in Japan. Systemic chemotherapy with $1 \mathrm{M}$ tegafur/0.4 M gimestat/ $1 \mathrm{M}$ ostat potassium (S-1) and cisplatin (CDDP) is recommended for inoperable or recurrent advanced gastric cancer as the first-line chemotherapy in the Japanese guideline [1]. S-1 is an oral fluoropyrimidine anticancer drug developed in Japan and contains gimeracil, which inhibits 5-fluorouracil (5-FU) degradation, and oteracil, which reduces the gastrointestinal toxicity of 5-FU. A phase III trial of S-1 and CDDP, named the SPIRIT trial, showed prolonged overall survival of 13 months [2]. In this study, the overall response rate was $54 \%$; however, only one of 87 patients administered S- 1 and CDDP achieved a clinical complete response (cCR). Here, we report two cases of gastric cancer with peritoneal carcinomatosis that successfully responded to S-1 and CDDP, leading to cCR. After achieving cCR, the two cases were followed by different procedures: (1) observation and (2) operation at the patient's request.

\section{Case 1}

A 60-year-old woman with no cancer-related past or family history visited a hospital with abdominal pain. No marked physical and laboratory findings were found. Gastrointestinal endoscopic fiberoscopy (GIF) was carried out and Borrmann type 3 advanced gastric carcinoma was found on the anterior wall of the stomach body (Fig. 1a). Computed tomography (CT) was carried out and regional lymph node metastases, peritoneal dissemination, and malignant ascitic fluid were suspected (Fig. 1b). Exploratory laparotomy was performed and peritoneal dissemination nodules were 

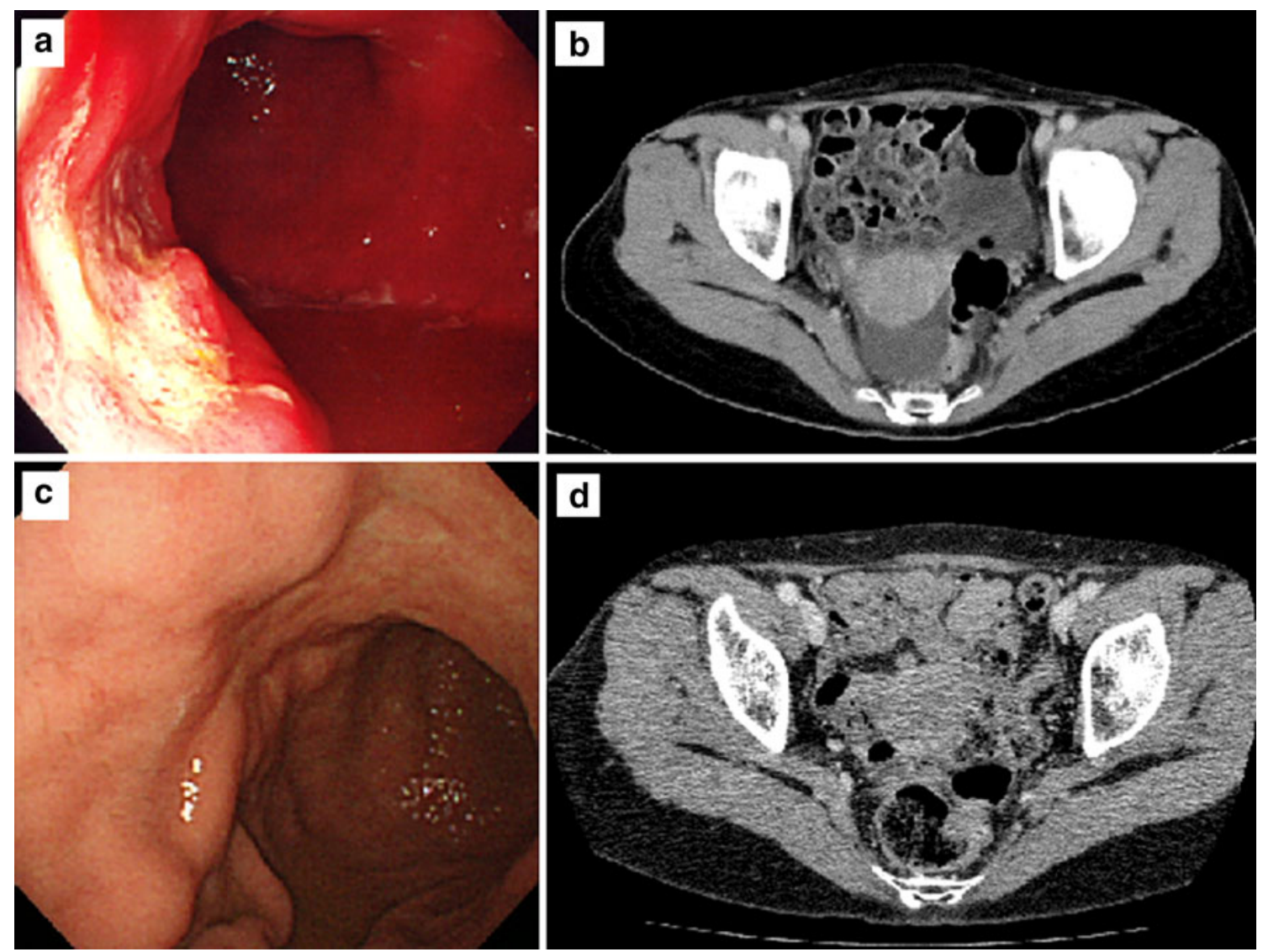

Fig. 1 Examination findings of GIF and CT in case 1. a, b Images before chemotherapy. c, $\mathbf{d}$ Images that confirmed cCR. Image a shows Borrmann type 3 with irregular ulcer formation on the anterior wall of

revealed. Pathological examination of the dissemination nodules led to the diagnosis of poorly differentiated tubular adenocarcinoma and signet-ring cell carcinoma. Because of peritoneal carcinomatosa, it was impossible to perform a curative operation, and the patient was referred to our institute. At our hospital, systemic chemotherapy consisting of S-1 and CDDP was started: $40 \mathrm{mg} / \mathrm{m}^{2}$ (50 mg/body) of $\mathrm{S}-1$ was given orally twice daily on day $1-21$, and $60 \mathrm{mg} / \mathrm{m}^{2}$ (85 mg/body) of CDDP was infused on day 8 , every 35 days. CT was carried out after two cycles of this regimen and showed the disappearance of the disseminated nodules and metastatic lymph nodes, and ascitic fluid was decreased. CT after six cycles showed that ascites had also disappeared (Fig. 1d). GIF (Fig. 1c) and positron emission tomography/CT (PET/CT) found no malignant signs, and thus the objective response was evaluated as cCR according to RECIST criteria (Response Evaluation Criteria in Solid Tumors), because a complete pathological examination was not done. Tumor markers were within normal limits. Overall, eight cycles of S-1 and CDDP were administered, but the dosage of CDDP was reduced to $70 \mathrm{mg} /$ body in cycles 6 and 7 , and $60 \mathrm{mg} / \mathrm{body}$ in cycle 8 the stomach body, but c suggests no lesion. Image b shows a moderate amount of ascitic fluid, but $\mathbf{d}$ shows fluid disappearance

because of grade 4 neutropenia in cycle 6 and 7 and grade 3 in cycle 8 (according to the National Cancer Institute's Common Terminology Criteria for Adverse Events version 4.0). After eight cycles of S-1 and CDDP, S-1 alone was administered for 42 months at the patient's request without grade 4 hematological adverse effects and grade 3 and 4 non-hematologic adverse effects. We suggested surgery, but it was rejected. After treatment with S-1 alone, only observation has been performed with no recurrence.

\section{Case 2}

A 63-year-old man with no cancer-related past or family history visited a hospital because of abdominal pain. No marked physical and laboratory findings were found. GIF was carried out and Borrmann type 3 advanced gastric cancer was found on the greater curvature of the lower stomach body (Fig. 2a). CT was carried out and regional lymph node metastases, marked ascites, and peritoneal dissemination were noted (Fig. 2b). Pathological examination of biopsy specimens from GIF led to the diagnosis 

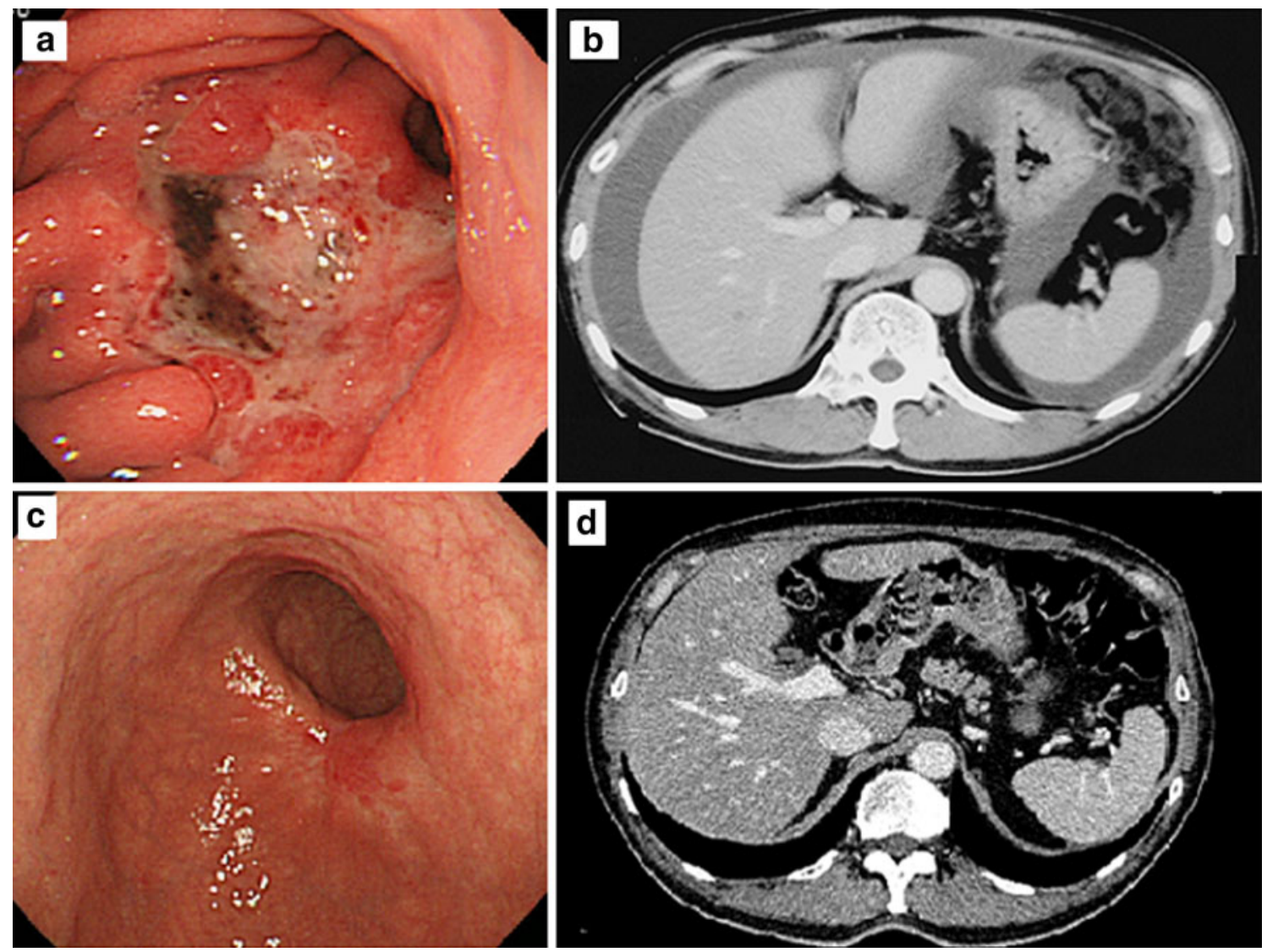

Fig. 2 Examination findings of GIF and CT in case 2. a, b Images before chemotherapy. c, d Images that confirmed cCR. Image a shows Borrmann type 3 tumor on the greater curvature of the lower stomach

of poorly differentiated tubular adenocarcinoma without HER2-neu overexpression. Because of marked ascites and peritoneal dissemination, it was impossible to perform a curative operation, and systemic chemotherapy with S-1/ CDDP was started using the same regimen as for case 1 . The dosages of S-1 and CDDP were $120 \mathrm{mg} / \mathrm{body} /$ day and $100 \mathrm{mg} /$ body on day 8. CT was carried out after two cycles of this regimen and showed the disappearance of metastatic lymph nodes, ascites, and peritoneal dissemination. CT examinations were carried out after every two cycles, and cCR was confirmed according to RECIST criteria. Eight cycles of S-1 and CDDP were performed; grade 3 anemia and grade 1 renal dysfunction were observed in cycle 5 and the dosage of CDDP was reduced to $90 \mathrm{mg} /$ body in cycles 6, 7, and 8. No other adverse effects were observed. CT (Fig. 2d), PET/CT, and the pathological examination of biopsy specimens from GIF (Fig. 2c) also confirmed cCR. We suggested surgery, the patient agreed, and distal gastrectomy and regional lymph node dissection were performed immediately. Viable cancer cells were not confirmed in the removed lymph nodes and peritoneal cavity, microscopically, and the therapeutic effect grade body, but c shows only a scar where malignant cells were not confirmed by pathological examination of biopsy specimens from GIF. Image $\mathbf{b}$ shows a lot of ascitic fluid, but $\mathbf{d}$ shows none

was 2 because viable cells in the stomach where the tumor was first found were within one-third and most of the nuclei had broken down. After the operation, adjuvant chemotherapy with S-1 alone was administered and, at present, no recurrence has been observed for 8 months.

\section{Discussion}

The National Comprehensive Cancer Network (NCCN) guideline showed that the definitive first-line chemotherapy for metastatic or locally advanced cancer without the indication of chemoradiation is trastuzumab with CDDP and fluoropyrimidine for HER2-neu overexpression-positive cases. It recommends DCF (docetaxel, cisplatin, and 5-FU), ECF (epirubicin, cisplatin, and 5-FU), ECF modulations, and FP (5-FU or capecitabine, and cisplatin) for HER2-neu overexpression-negative cases [3]. On the other hand, the Japanese guideline shows that S- 1 and CDDP are regarded as having the best prognosis as first-line chemotherapy on the basis of two phase III studies, JCOG9912 [4] and SPRITS trials [2]. JCOG9912 showed that S-1 is non-inferior 
Table 1 Details of 54 case reports

\begin{tabular}{|c|c|c|c|c|c|}
\hline \multirow[t]{2}{*}{ Authors } & \multirow{2}{*}{$\begin{array}{l}\text { Regimen achieving } \\
\text { cCR }\end{array}$} & \multicolumn{3}{|c|}{ Chemotherapy after cCR } & \multirow[t]{2}{*}{ Publication } \\
\hline & & $\begin{array}{l}\text { Chemotherapy } \\
\text { lines }\end{array}$ & Chemotherapy & Operation & \\
\hline Nunobe et al. & $\mathrm{S}-1$ and fractionated CDDP & 1 & Stopped & Yes & Hepatogastroenterology. 59:307-9, 2012 \\
\hline Mazzola et al. & Cape and 1-OHP & 1 & Continued & & Tumori. 97:115-8, 2011 \\
\hline Ina et al. & S-1 and TXL & 1 & Stopped & & Gan To Kagaku Ryoho. 36:979-81, 2009 \\
\hline Ina et al. & S-1 and CDDP (24 $\mathrm{h}$ infusion) & 1 & Unknown & & Oncol Rep. 20:259-64, 2008 \\
\hline Ina et al. & S-1 and CDDP (24 h infusion) & 1 & Unknown & & Oncol Rep. 20:259-64, 2008 \\
\hline Mizutani et al. & Paclitaxel and doxifluridine & 1 & Continued & & Int J Clin Oncol. 11:471-4, 2006 \\
\hline Morishita et al. & S-1 alone & 3 & Continued & & Hepatogastroenterology. 52:1933-5, 2005 \\
\hline Michiwa et al. & S-1 and low dose CDDP & 1 & Unknown & & J Exp Clin Cancer Res. 21:609-11, 2002 \\
\hline Tsukioka et al. & S-1 alone & 2 & Continued & & Jpn J Clin Oncol. 31:450-3, 2001 \\
\hline Tanemura et al. & $\mathrm{CDDP}, \mathrm{MMC}$, and 5-FU & 1 & Stopped & Yes & J Surg Oncol. 38:26-32, 1988 \\
\hline Iwase et al. & UFT and MMC & 1 & Continued & & Gan No Rinsho. 33:729-35, 1987 \\
\hline Hagin et al. & 5-FU, MMC, and DXR & 1 & Stopped & & Am J Gastroenterol. 80:835-7, 1985 \\
\hline Kobayashi et al. & S-1 and low dose CDDP & 1 & Stopped & & Gan To Kagaku Ryoho. 38:1951-3, 2011 \\
\hline Fukunaga et al. & CPT-11 and CDDP & 1 & Continued & & Gan To Kagaku Ryoho. 37:2418-20, 2010 \\
\hline Kinoshita et al. & S-1, CDDP, and lentinan & 1 & Continued & & Gan To Kagaku Ryoho. 37:707-1, 2010 \\
\hline Tokunaga et al. & S-1 alone & 2 & Continued & & Gan To Kagaku Ryoho. 37:703-6, 2010 \\
\hline Tokunaga et al. & S-1 alone & 2 & Continued & & Gan To Kagaku Ryoho. 37:703-6, 2011 \\
\hline Kimura et al. & S-1 alone & 1 & Continued & & Gan To Kagaku Ryoho. 37:1565-8, 2010 \\
\hline Megumi et al. & CDDP and GEM & 3 & Stopped & & Gan To Kagaku Ryoho. 37:1373-6, 2010 \\
\hline Hosaka et al. & S-1 and DOC & 1 & Continued & & Gan To Kagaku Ryoho. 36:2637-9, 2009 \\
\hline Aoki et al. & S-1 alone & 2 & Unknown & & Gan To Kagaku Ryoho. 36:2272-4, 2009 \\
\hline Matsumura et al. & S-1 alone & 2 & Continued & & Gan To Kagaku Ryoho. 36:2284-6, 2009 \\
\hline Matsuyama et al. & S-1 and TXL & 2 & Continued & & Gan To Kagaku Ryoho. 36:2297-9, 2009 \\
\hline Kishimoto et al. & TXL alone & 2 & Continued & & Gan To Kagaku Ryoho. 35:2057-9, 2008 \\
\hline Okabe et al. & TXL and $5^{\prime}$-DFUR & 1 & Continued & & Gan To Kagaku Ryoho. 36:115-8, 2009 \\
\hline Fujimoto et al. & CPT-11 and low dose CDDP & 2 & Continued & & Gan To Kagaku Ryoho. 36:313-5, 2009 \\
\hline Sekino et al. & S-1 and CDDP & 1 & Continued & & Gan To Kagaku Ryoho. 36:847-9, 2009 \\
\hline Kitajima et al. & TXL and $5^{\prime}$-DFUR & 1 & Continued & & Gan To Kagaku Ryoho. 36:851-4, 2009 \\
\hline Ishigami et al. & S-1 alone & 2 & Continued & & Gan To Kagaku Ryoho. 35:1197-9, 2008 \\
\hline Otsuki et al. & S-1 and CDDP & 1 & Unknown & & Gan To Kagaku Ryoho. 35:1387-90, 2008 \\
\hline Mazaki et al. & S-1 and CPT-11 & 1 & Continued & & Gan To Kagaku Ryoho. 35:1583-6, 2008 \\
\hline Oshiro et al. & S-1 and CPT-11 & 1 & Continued & & Gan To Kagaku Ryoho. 34:2111-3, 2007 \\
\hline Imamura et al. & S-1 and CPT-11 & 1 & Stopped & & Gan To Kagaku Ryoho. 34:2114-6, 2007 \\
\hline Okuda et al. & S-1 alone & 2 & Continued & & Gan To Kagaku Ryoho. 34:1659-61, 2007 \\
\hline Fukasawa et al. & TXL and $5^{\prime}$-DFUR & 6 & Continued & & Gan To Kagaku Ryoho. 33:235-8, 2006 \\
\hline Kodama et al. & S-1 and TXL & 1 & Unknown & & Gan To Kagaku Ryoho. 33:1159-62, 2006 \\
\hline Shoji et al. & S-1 and low dose CDDP & 1 & Continued & & Gan To Kagaku Ryoho. 32:1457-9, 2005 \\
\hline Takashima et al. & DOC & 2 & Continued & & Gan To Kagaku Ryoho. 32:1041-4, 2005 \\
\hline Morishita et al. & S-1 and CPT-11 & 1 & Continued & & Gan To Kagaku Ryoho. 32:847-9, 2005 \\
\hline Yasumoto et al. & S-1 alone & 1 & Continued & & Gan To Kagaku Ryoho. 31:1565-7, 2004 \\
\hline Nomura et al. & S-1 and DOC & 2 & Continued & & Gan To Kagaku Ryoho. 31:1579-82, 2004 \\
\hline Chou et al. & TXL & 2 & Continued & & Gan To Kagaku Ryoho. 31:605-7, 2004 \\
\hline Shiraishi et al. & S-1 alone & 1 & Continued & & Gan To Kagaku Ryoho. 31:589-92, 2004 \\
\hline Yano et al. & S-1 alone & 1 & Continued & & Gan To Kagaku Ryoho. 29:1461-4, 2002 \\
\hline Suzuki et al. & CPT-11 and CDDP & 2 & Continued & & Gan To Kagaku Ryoho. 30:859-61, 2003 \\
\hline Tsuchiya et al. & UFT-E & 3 & Continued & & Gan To Kagaku Ryoho. 29:615-8, 2002 \\
\hline Iwase et al. & S-1 and CDDP & 1 & Stopped & & Gan To Kagaku Ryoho. 28:1441-4, 2001 \\
\hline Iwase et al. & S-1 and CDDP & 1 & Continued & & Gan To Kagaku Ryoho. 29:1235-9, 2002 \\
\hline
\end{tabular}


Table 1 continued

\begin{tabular}{|c|c|c|c|c|c|}
\hline \multirow[t]{2}{*}{ Authors } & \multirow{2}{*}{$\begin{array}{l}\text { Regimen achieving } \\
\text { cCR }\end{array}$} & \multicolumn{3}{|c|}{ Chemotherapy after cCR } & \multirow[t]{2}{*}{ Publication } \\
\hline & & $\begin{array}{l}\text { Chemotherapy } \\
\text { lines }\end{array}$ & Chemotherapy & Operation & \\
\hline Onoyama et al. & UFT & 1 & Stopped & & Gan To Kagaku Ryoho. 27:1731-5, 2000 \\
\hline Yamada et al. & S-1 alone & 1 & Continued & & Gan To Kagaku Ryoho. 27:2139-43, 2000 \\
\hline Kanayama et al. & 5-FU and LV & 1 & Continued & & Gan To Kagaku Ryoho. 24:2147-50, 1997 \\
\hline Okugawa et al. & 5-FU, LV, and CDDP & 1 & Continued & & Gan To Kagaku Ryoho. 20:1059-62, 1993 \\
\hline Iwase et al. & UFT & 2 & Continued & & Gan To Kagaku Ryoho. 19:2235-7, 1992 \\
\hline Tanemura et al. & 5-FU, MMC, and CDDP & 1 & Stopped & Yes & Gan To Kagaku Ryoho. 14(3 Pt 1):728-31, 1987 \\
\hline
\end{tabular}

l-OHP oxaliplatin, TXL paclitaxel, MMC mitomycin C, UFT tegaer/uracil, DXR doxorubicin, CPT-11 irinotecan hydrochloride, GEM gemcitabine, DOC docetaxel, $5^{\prime}$-DFUR $5^{\prime}$-doxifluridine, $U F T$-E enteric tegaer/uracil

to 5-FU in overall survival for non-resectable or recurrent advanced gastric cancer. SPIRITS showed that S-1 and CDDP is superior to S-1 alone in overall survival. Our two patients were treated with S-1 and CDDP according to the Japanese gastric cancer treatment guideline, and cCR was achieved.

The SPRITS trial showed only one case of cCR [2]; however, detailed data were not shown. Fifty-four reports of cCR cases of advanced non-resectable or metastatic gastric cancer with oral or intravenous anticancer drugs were identified through the PubMed system and other related websites (Table 1). Treatment is included in 45 reports; 35 of 45 cases (77.8\%) continued chemotherapy and 3 of 27 recurred during continued chemotherapy. Seven of 45 cases stopped chemotherapy after achieving $\mathrm{cCR}$ on evaluation and one recurrence was reported. The durations of cCR are shown in 49 case reports and the range of durations is $2-90$ months and the median is 17 months. Three of 45 patients $(6.5 \%)$ had undergone operations and two showed a pathological complete response, but in the other, viable cancer cells were proven pathologically.

Treatment after cCR evaluation has not been discussed, and there is no consensus. No previously published case reports about cCR compared the treatment options. In this report, we show two patients choosing different paths after achieving cCR by chemotherapy. Of our two patients, one wished to undergo surgery and the other wanted to be observed. It is unknown which decision is correct; however, it is thought that the decision to observe should be made after careful consideration, because recurrence or residues of pathological viable cancer cells have been seen to some degree. More investigation is warranted to answer this clinical question.

Conflict of interest The authors declare that they have no conflict of interest.

\section{References}

1. Japanese Gastric Cancer Association (2011) Japanese gastric cancer treatment guidelines 2010 (ver. 3). Gastric Cancer 14:113-123

2. Koizumi W, Narahara H, Hara T et al (2008) S-1 plus cisplatin versus $\mathrm{S}-1$ alone for first-line treatment of advanced gastric cancer (SPIRITS trial): a phase III trial. Lancet Oncol 9:215-221

3. National Comprehensive Cancer Network: NCCN clinical practice guidelines in oncology, gastric cancer version 2.2012. http://www. nccn.org/professionals/physician_gls/f_guidelines.asp. Accessed 15 Nov 2012

4. Boku N, Yamamoto S, Fukuda $H$ et al (2009) Fluorouracil versus combination of irinotecan plus cisplatin versus S-1 in metastatic gastric cancer: a randomised phase 3 study. Lancet Oncol 10:1063-1069 